\title{
Delayed discharge after major surgical procedures in Ontario, Canada: a population-based cohort study
}

\author{
Angela Jerath MD MSc, Jason Sutherland PhD, Peter C. Austin PhD, Dennis T. Ko MD MSc, \\ Harindra C. Wijeysundera MD PhD, Stephen Fremes MD MSc, Paul Karanicolas PhD, Daniel McCormack MSc, \\ Duminda N. Wijeysundera MD PhD
}

Cite as: CMAJ 2020 November 16;192:E1440-52. doi: 10.1503/cmaj.200068

\begin{abstract}
BACKGROUND: Addressing nonmedical reasons for delays in hospital discharge is important for improving the flow of patients through acute care hospital beds. Because this problem is understudied among adult surgical patients, we examined the incidence of and identified factors associated with delayed hospital discharge after major elective and emergency surgical procedures in acute care institutions.
\end{abstract}

METHODS: Using health administrative data, we retrospectively compared adults with and without delayed discharge after 18 major elective and emergency surgical procedures between 2006 and 2016 in Ontario hospitals. We identified delayed discharge using the alternate level of care code, applied to patients who are medically fit for dis- charge but remain in an acute care hospital bed. We used hierarchical logistic regression modelling to determine factors associated with delayed discharge.

RESULTS: Our cohort included 595782 patients who underwent elective procedures and 180478 who underwent emergency procedures. Delayed discharge accounted for 635607 hospital days, of which $81.7 \%$ were related to admissions for emergency surgery. Delayed discharge affected $3.1 \%$ of patients who underwent elective surgery and $19.6 \%$ of those who underwent emergency procedures. Days attributed to delayed discharge formed about onethird of patients' total hospital stay for both surgical groups. The rate of delayed discharge across surgical specialties showed high variability (from
$0.9 \%$ for lung resection or nephrectomy to $9.3 \%$ for peripheral arterial disease procedures in the elective surgery group, and from $3.8 \%$ for cardiac procedures to $33.8 \%$ for peripheral arterial disease procedures in the emergency surgery group). Risk factors for delayed discharge were older age, female sex, chronic disease burden and increasing hospital size.

INTERPRETATION: Delayed discharge for nonmedical reasons was more common after emergency surgery than after elective surgery, and rates varied across surgery type. Optimizing early discharge planning, evaluating the variation in delayed discharge at the hospital level and improving local access to community care services could be next steps to addressing this problem.
$\mathbf{R}$ ising hospital admissions and the complex care needs of an aging population have increased the need for acute care hospital beds to be used efficiently, particularly in publicly funded health care systems. ${ }^{1-3}$ The management of inpatients whose hospital discharge is delayed for nonmedical reasons is a potential area of focus to improve the flow of patients through acute care hospital beds. Most patients with delayed discharge are waiting for home support services or transfer to a more appropriate community-based setting (e.g., rehabilitation or long-term care). ${ }^{4,5}$ Delay of discharge after a patient is designated medically fit to leave hospital is a major problem for health care systems, affecting wait times and costs and leading to delivery of health care in unsafe locations (i.e., "hallway medicine"). ${ }^{5}$ In Canada, an estimated $13 \%$ of hospital beds are occupied by patients deemed medically fit for discharge. ${ }^{5}$

Most prior studies examining delayed discharge have involved heterogeneous medical and trauma populations..$^{4,6,7}$ Those studies found that patients at risk of delayed discharge were older individuals with mental health concerns in smaller hospitals. ${ }^{4,8}$ Delayed discharge among adult patients following major surgery, especially emergency procedures, remains understudied. The demand for both surgery and hospital beds, 
particularly for older patients with medically complex care needs, is rising. ${ }^{9}$ Delayed discharge thwarts the efforts of clinicians and health care managers to optimize use of acute care beds, plan discharges and access community services. We conducted a population-based cohort study in Ontario, Canada, to define the incidence of and identify factors associated with delayed discharge after several commonly performed major elective and emergency surgical procedures.

\section{Methods}

\section{Study design and data sources}

We conducted a retrospective population-based cohort study using data for patients who underwent surgery in Ontario, Canada, between January 2006 and December 2016. We linked various health care databases using unique patient identifiers. The health care databases and variables that we used are fully described in Appendix 1, Tables S1 and S2 (available at www. cmaj.ca/lookup/doi/10.1503/cmaj.200068/tab-related-content). ${ }^{10-12}$ We extracted data for demographic characteristics, comorbidities, perioperative care needs (including invasive monitoring and admission to the intensive care unit), type of surgery, type of hospital, postoperative complications (including infection, bleeding, stroke, myocardial ischemia, respiratory failure and acute kidney injury) and patient outcomes. Study reporting follows the Strengthening the Reporting of Observational Studies in Epidemiology guidelines. ${ }^{13}$

\section{Study cohort}

We identified adults who underwent selected major elective and emergency surgical procedures requiring a postoperative hospital stay of at least 2 days. According to our previous work, ${ }^{11,12}$ this 2-day minimum stay ensured selection of patients who would be most affected by a delayed discharge and assessment of those who survived surgery but might have gone on to need non-acute care services. We included only patients older than 40 years on the basis of previous studies and clinical experience indicating that such individuals are more likely to undergo complex, major, high-risk (e.g., aortic, intrathoracic) and intermediate-risk (e.g., orthopedic, intraabdominal) surgery ${ }^{14}$ that requires admission for postoperative monitoring and care and are more likely to present with multiple chronic health problems that slow down postoperative recovery and affect the need for community care services. ${ }^{11,15}$

The elective surgery cohort included patients who underwent the following 9 types of surgery: vascular abdominal aortic surgery (open and endovascular aortic repair), peripheral arterial disease procedures (above- or below-knee amputation, lower limb revascularization), lung resection (open pneumonectomy, open and thoracoscopic partial lung resection), lower gastrointestinal procedures (colorectal resection), nephrectomy, neurosurgery (open craniotomy, posterior fossa surgery), spine surgery, total joint (hip or knee) replacement surgery and cardiac surgery (aortocoronary bypass, valve repair or replacement, aortic surgery). The 9 surgery types for patients in the emergency cohort were cardiac surgery, vascular abdominal aortic surgery, peripheral arterial disease procedures, lower gastrointestinal procedures, neurosurgery, solid organ transplant (kidney, liver, lung, heart, multivisceral), hip fixation, joint replacement and spine surgery. We selected these procedures because they are commonly performed at many hospitals and are associated with a challenging patient-case mix (i.e., high burden of comorbidity, older age) and complex postoperative recovery with high morbidity rates. ${ }^{16}$ We included specialized cardiac and transplant procedures because the patients typically receive structured perioperative care from a multidisciplinary team (including nurses, physicians, social workers, physiotherapists and occupational therapists). We identified the surgical procedures using the Canadian Classification of Health Interventions and CorHealth procedure codes (see Appendix 1, Table S3 ${ }^{12}$ ). For patients who underwent multiple eligible operations during the study period, we included only the first procedure.

\section{Outcomes}

The main outcome was a delay in hospital discharge for nonmedical reasons, which we identified using the code for alternate level of care in the Discharge Abstract Database of the Canadian Institute for Health Information ( $\mathrm{ClHI}$ ). The alternate level of care code is applied to patients who occupy an acute care inpatient bed but no longer require the resources or services provided in that care setting by a staff physician or hospital delegate. ${ }^{17}$ A standardized approach to collecting data for alternate level of care days has been established since 1989, ${ }^{1,17}$ with the presence of this type of care (yes/no), the number of days of alternate level of care and the duration of the acute care hospitalization being recorded. Alternate level of care starts when the patient is deemed fit for discharge and stops when the patient leaves the alternate level of care setting or reverts back to acute care status. $\mathrm{ClHI}$ provides guidance on differentiating acute care status (i.e., active treatment, diagnostics, close monitoring, 1 or more daily physician visits, 2 or more nursing or allied health visits, complex physical or mental symptom management) from alternate level of care status (i.e., medically stable, with care needs that can be met in another setting, such as the patient's home with home care, a complex continuing care setting, a rehabilitation facility or on an outpatient basis). ${ }^{1}$ Previous re-abstraction studies have reported good reliability between charts and administrative data for alternate level of care codes (99.8\%-100\%), hospital admission codes (99.9\%) and discharge codes (99.9\%).1,18,19 The alternate level of care code has been used for regular reporting by $\mathrm{CIHI}$, provincial quality agencies (e.g., Health Quality Ontario) and other studies examining delayed discharge..$^{1,7,20,21}$

\section{Statistical analysis}

We described temporal annual trends and monthly seasonal variation in the proportion of patients with alternate level of care (i.e., delayed discharge) among patients undergoing elective or emergency surgery. We compared proportions of patients designated as alternate level of care and proportions of the hospital stay attributed to alternate level of care days across surgical specialties. 
We also compared patient characteristics, hospital characteristics and postoperative outcomes (days alive and out of hospital, complications, death, length of stay, discharge disposition) between patients with and without the alternate level of care designation within the elective and emergency surgery groups. Days alive and out of hospital is a postoperative outcome that captures mortality, hospital length of stay, hospital readmissions and days spent in long-term care during any specified period. Validation studies of this outcome have shown that it is sensitive to level of patient complexity (e.g., advancing age, number of chronic health issues), complexity of the surgical procedure and postoperative complications. ${ }^{11,15}$ We calculated days alive and out of hospital at 30, 90 and 180 days, as previously described. ${ }^{11,15}$ As a brief example, to calculate the number of days alive and out of hospital at day 30 , the number of days spent in hospital and long-term care after surgery was subtracted from 30 days. Therefore, for a patient who survived surgery and was discharged 10 days after the index date of surgery, was readmitted for 2 days on postoperative day 20 and had no days in long-term care, the number of days alive and out of hospital at day 30 was 18 days. If death occurred within the specified time frame, a value of 0 days was assigned.

We used a multivariable logistic regression model to estimate the adjusted association of patient-level factors (age, sex, coronary artery disease, myocardial infarction, asthma, chronic obstructive pulmonary disease, cancer, chronic liver disease, chronic renal dysfunction, hypertension, stroke, dementia, atrial fibrillation, rural residence, neighbourhood income quintile, duration of surgery, type of surgery, trauma and year) and hospital-level factors (academic status, number of beds and hospital-specific proportion of alternate level of care patients) with designation of alternate level of care. We included the total number of hospital beds in the model as a 3 -knot restricted cubic spline to account for possible nonlinear associations with the log-odds of alternate level of care. ${ }^{22}$ We

Table 1: Surgery-specific volumes, delayed discharge, length of hospital stay and mortality

\begin{tabular}{|c|c|c|c|c|c|c|c|c|}
\hline \multirow[b]{2}{*}{ Type of surgery } & \multirow[b]{2}{*}{$\begin{array}{l}\text { No. of } \\
\text { procedures }\end{array}$} & \multirow[b]{2}{*}{$\begin{array}{l}\text { No. of } \\
\text { hospitals }\end{array}$} & \multirow[b]{2}{*}{$\begin{array}{l}\text { No. (\%) of patients } \\
\text { with ALC* }\end{array}$} & \multicolumn{3}{|c|}{$\begin{array}{c}\text { Type of care; } \\
\text { length of stay, } d, \text { median (IQR) }\end{array}$} & \multicolumn{2}{|c|}{$\begin{array}{l}\text { Mortality time frame; } \\
\text { no. }(\%) \text { of patients }\end{array}$} \\
\hline & & & & Acute & $A L C^{*}$ & $\begin{array}{l}\text { Total in } \\
\text { hospital }\end{array}$ & 30-d & $1-y r$ \\
\hline \multicolumn{9}{|l|}{ Elective } \\
\hline AAA repair & 16049 & 29 & $345(2.1)$ & $6(3-8)$ & $5(2-9)$ & $6(3-8)$ & $332(2.1)$ & $973(6.1)$ \\
\hline Joint replacement & 356581 & 70 & $10546(3.0)$ & $3(3-5)$ & $3(1-5)$ & $3(3-5)$ & $678(0.2)$ & $3938(1.1)$ \\
\hline Lower GI & 70959 & 91 & $1487(2.1)$ & $6(4-9)$ & $5(3-11)$ & $6(4-9)$ & $1085(1.5)$ & $4161(5.9)$ \\
\hline Nephrectomy & 17051 & 53 & $151(0.9)$ & $4(3-6)$ & $6(3-12)$ & $4(3-6)$ & $119(0.7)$ & $912(5.3)$ \\
\hline Cardiac & 53579 & 12 & $1687(3.1)$ & $7(5-9)$ & $3(2-6)$ & $7(5-9)$ & $943(1.8)$ & $2233(4.2)$ \\
\hline Lung & 25065 & 33 & $218(0.9)$ & $4(3-7)$ & $6(3-9)$ & $4(3-7)$ & $330(1.3)$ & $2491(9.9)$ \\
\hline Neurosurgery & 7643 & 12 & $488(6.4)$ & $3(2-6)$ & $5(2-10)$ & $4(2-6)$ & $192(2.5)$ & $2264(29.6)$ \\
\hline $\begin{array}{l}\text { Peripheral } \\
\text { arterial disease }\end{array}$ & 13958 & 58 & $1303(9.3)$ & $5(3-8)$ & $5(3-11)$ & $5(3-9)$ & $319(2.3)$ & $1677(12.0)$ \\
\hline Spine & 34897 & 23 & $2052(5.9)$ & $3(2-5)$ & $3(1-6)$ & $3(2-6)$ & $120(0.3)$ & $674(1.9)$ \\
\hline Total & 595782 & 95 & $18277(3.1)$ & $4(3-6)$ & $3(2-6)$ & $4(3-6)$ & $4118(0.7)$ & $19323(3.2)$ \\
\hline \multicolumn{9}{|l|}{ Emergency } \\
\hline AAA repair & 3273 & 29 & $255(7.8)$ & $9(5-16)$ & $8(4-16)$ & $10(5-17)$ & $581(17.8)$ & $864(26.4)$ \\
\hline Hip fixation & 24156 & 69 & $7331(30.3)$ & $7(5-11)$ & $6(3-14)$ & $8(6-15)$ & $1682(7.0)$ & $5321(22.0)$ \\
\hline Joint replacement & 45220 & 68 & $14156(31.3)$ & $8(5-13)$ & $6(3-13)$ & $9(6-16)$ & $3324(7.4)$ & $10131(22.4)$ \\
\hline Lower GI & 31290 & 83 & $3363(10.7)$ & $11(7-19)$ & $8(3-18)$ & $12(7-21)$ & 3359 (10.7) & $7499(24.0)$ \\
\hline Transplant & 7940 & 7 & $350(4.4)$ & $10(7-18)$ & $7(4-14)$ & $10(7-18)$ & $144(1.8)$ & $493(6.2)$ \\
\hline Cardiac & 33433 & 12 & $1269(3.8)$ & $11(8-17)$ & $4(2-8)$ & $11(8-17)$ & $1335(4.0)$ & $2614(7.8)$ \\
\hline Neurosurgery & 13814 & 12 & $1976(14.3)$ & $7(4-13)$ & $7(3-17)$ & $7(4-14)$ & $1468(10.6)$ & $4573(33.1)$ \\
\hline $\begin{array}{l}\text { Peripheral } \\
\text { arterial disease }\end{array}$ & 12220 & 58 & 4135 (33.8) & $14(8-24)$ & $8(4-20)$ & $16(9-30)$ & $1202(9.8)$ & $3619(29.6)$ \\
\hline Spine & 9132 & 24 & $2610(28.6)$ & $10(6-18)$ & $6(3-13)$ & $12(7-22)$ & $351(3.8)$ & $1499(16.4)$ \\
\hline Total & 180478 & 86 & 35445 (19.6) & $9(6-16)$ & $6(3-14)$ & $10(7-18)$ & $13446(7.5)$ & $36613(20.3)$ \\
\hline
\end{tabular}

Note: $\mathrm{AAA}=$ abdominal aortic aneurysm, $\mathrm{ALC}=$ alternate level of care, $\mathrm{GI}$ = gastrointestinal, $\mathrm{IQR}$ = interquartile range.

*The ALC code was used to define patients with delayed discharge. 
used a hierarchical logistic regression model that accounted for clustering of patients within hospitals.

To evaluate the impact of postoperative complications on delayed discharge, we conducted a sensitivity analysis by including this variable within the model described above. To characterize the impact of the individual hospital on the probability of alternate level of care designation across hospitals, we calculated the intraclass coefficient and median odds ratio (OR) using the estimated variance of the random intercepts from the hierarchical logistic regression model. ${ }^{23}$ The intraclass coefficient quantifies the proportion of the total variation in outcome that is due to systematic differences between hospitals described by the ratio between variances. The median OR is a measure of heterogeneity for use with binary outcomes that is adjusted for patient-level covariables. It is the median value obtained in comparison of the adjusted odds of the alternate level of care designation if the same individual underwent surgery at 2 different randomly selected hospitals. The median OR compares higherranked hospitals with lower-ranked hospitals and thus always has a value of 1 or more.

We conducted the analyses using SAS version 9.4 (SAS Institute) and R statistical software (v.0.98.1091; R Core
Team). Two-sided $p$ values less than 0.05 were considered statistically significant.

\section{Ethics approval}

Use of the data was authorized under section 45 of Ontario's Personal Health Information Protection Act and approved by the Sunnybrook Health Sciences Centre research ethics board.

\section{Results}

The cohort consisted of 776260 patients treated at 95 hospitals, 595782 patients in the elective surgery group and 180478 in the emergency surgery group.

\section{Incidence and temporal trends}

Overall, $3.1 \%$ of patients in the elective surgery group and $19.6 \%$ of those in the emergency surgery group experienced delayed discharge (Table 1). The incidence of delayed discharge varied from $0.9 \%$ (nephrectomy and lung surgery) to $9.3 \%$ (peripheral arterial disease procedures) in the elective surgery group and from $3.8 \%$ (cardiac surgery) to $33.8 \%$ (peripheral arterial disease procedures) in the emergency surgery group (Figure 1).

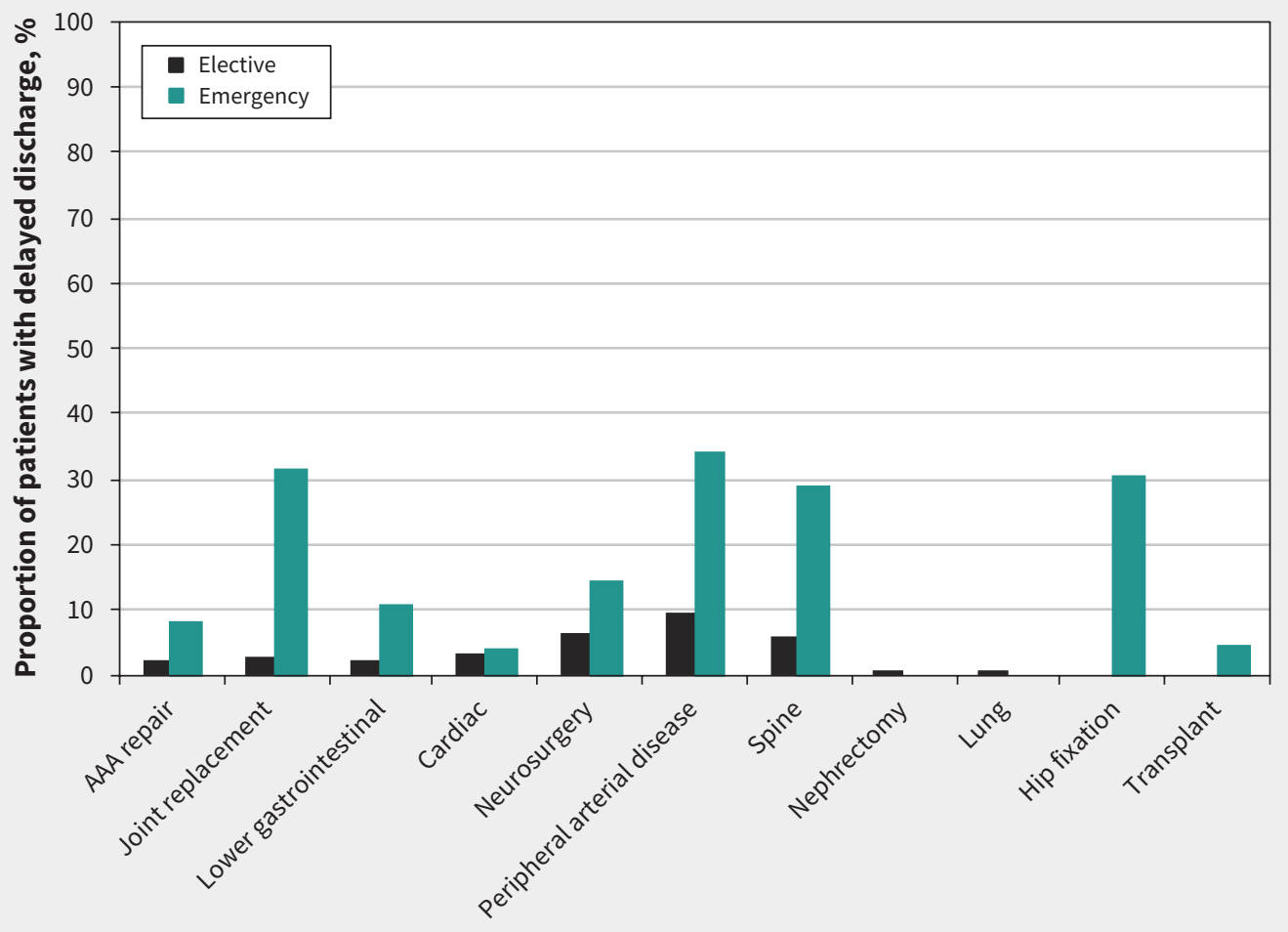

Type of surgical procedure

Figure 1: Proportion of patients affected by delayed discharge between 2006 and 2016 in Ontario, according to type of surgery performed. Patients with delayed discharge were defined as those with code for alternate level of care. Note: AAA = abdominal aortic aneurysm. 
From 2006 to 2016, a total of 635607 hospital days were attributed to delayed discharge for nonmedical reasons, with $519240(81.7 \%)$ being related to admissions for emergency surgery. Overall, alternate level of care days accounted for $3.6 \%$ of total hospital stay after elective surgery (i.e., 116367 alternate level of care days out of 3266409 total days in hospital) and $17.1 \%$ of total hospital stay after emergency surgery (i.e., 519240 alternate level of care days out of 3038620 total days in hospital). For elective surgery, the annualized proportion of patients affected by delayed discharge increased from 2006 to 2009 and

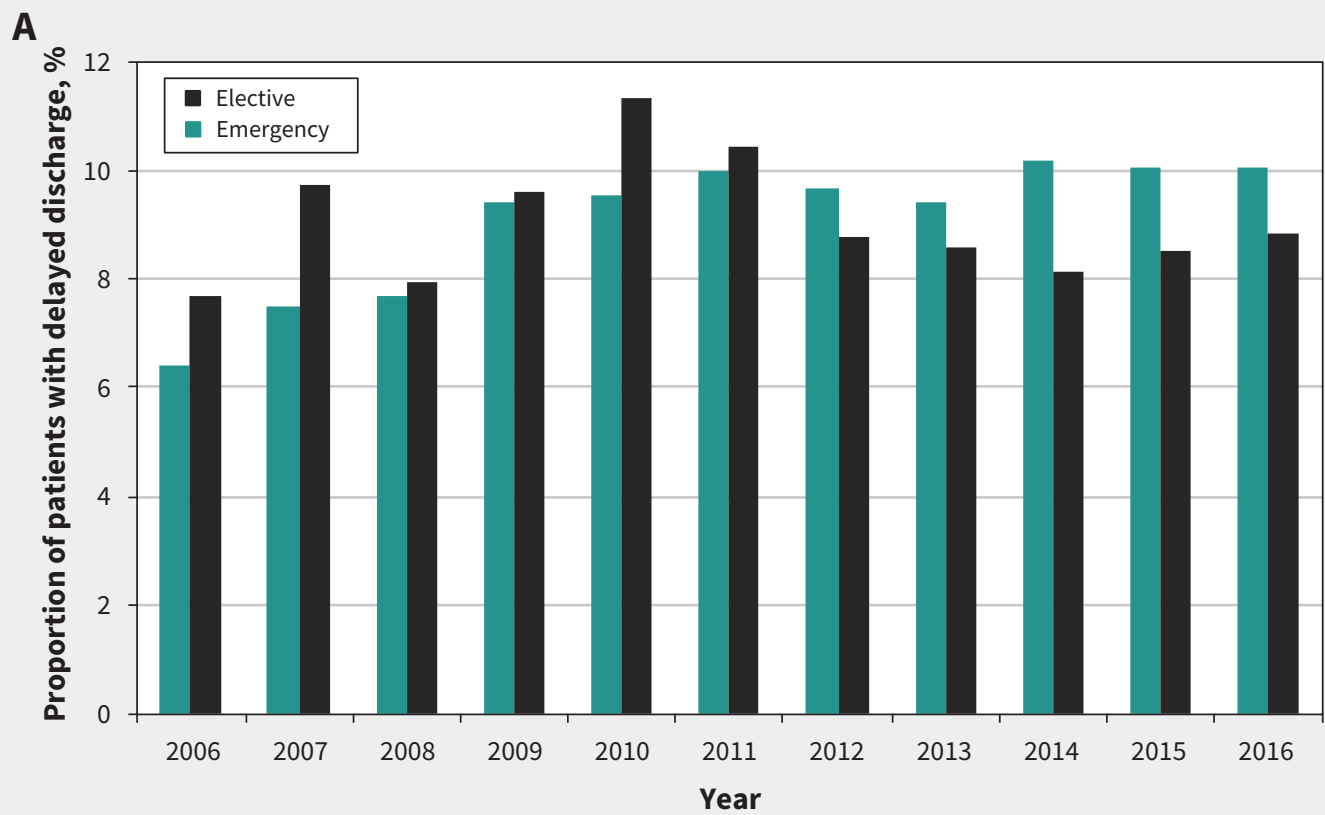

\section{B}

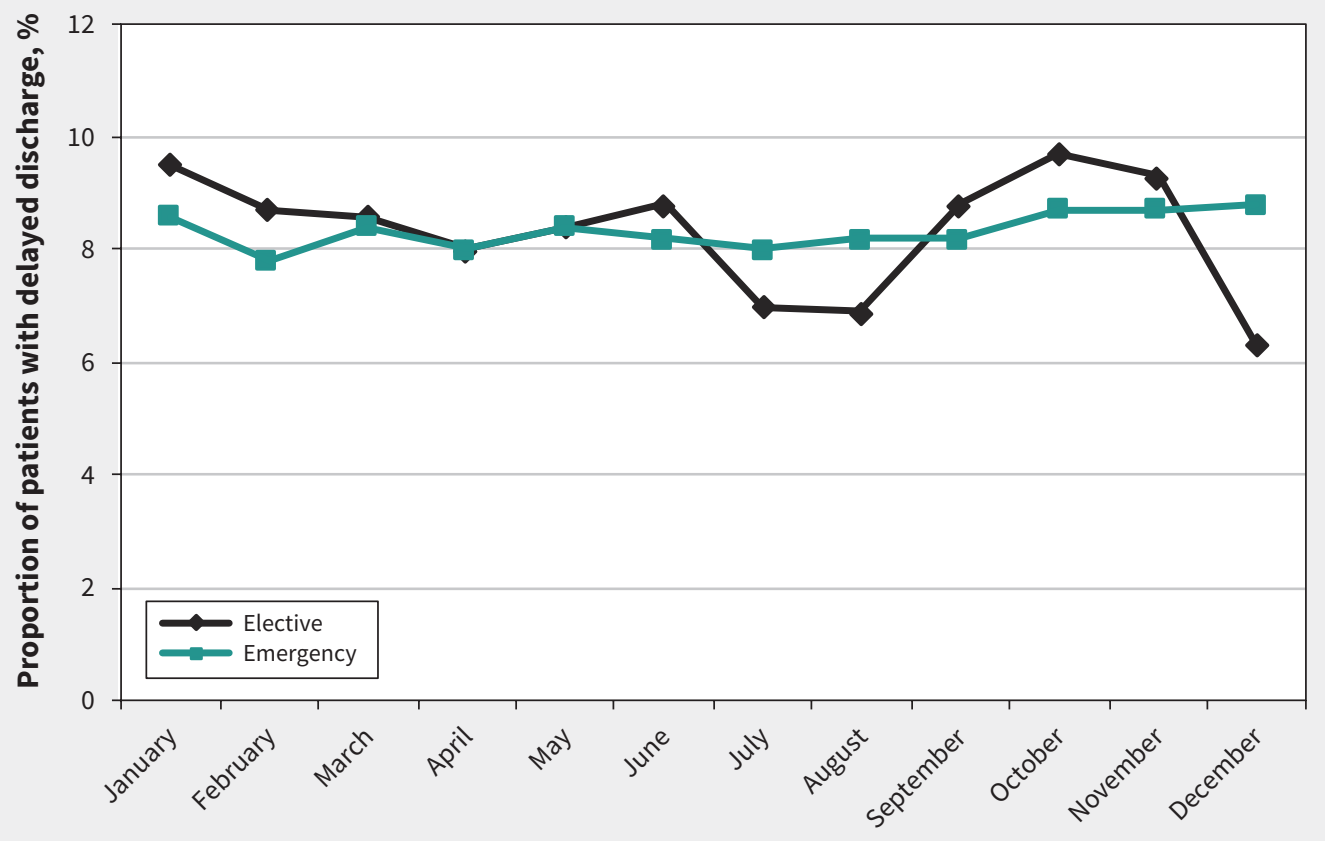

Month

Figure 2: Annual (A) and seasonal (B) trends in proportion of patients affected by delayed discharge, defined as those with code for alternate level of care. Seasonal trends are based on combined data from all years. 


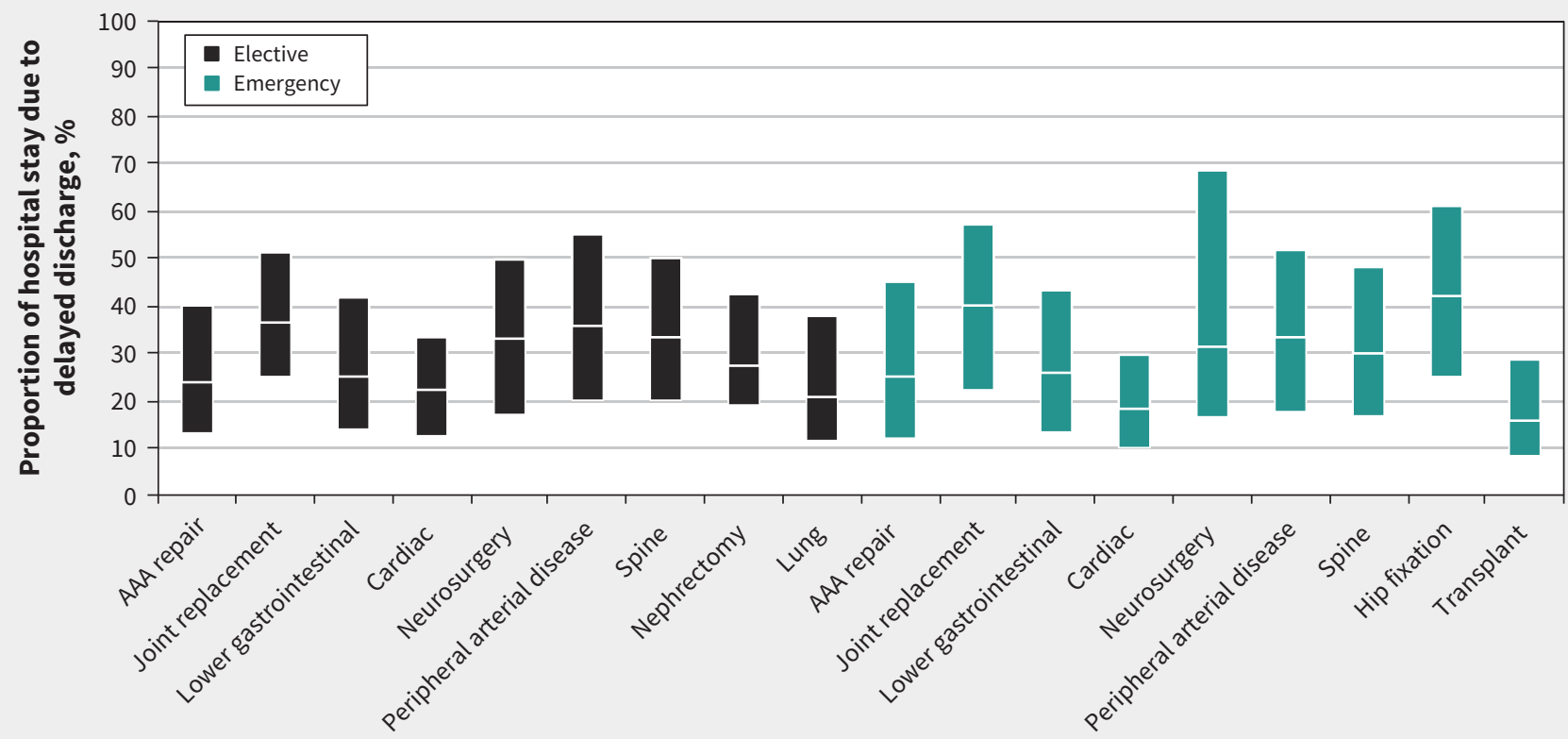

Type of surgical procedure

Figure 3: Proportion of hospital stay (measured in days) attributed to delayed discharge, by type of surgery. The horizontal white line within each bar indicates the median value, and the solid bars below and above this line represent the lower and upper quartiles. Note: AAA = abdominal aortic aneurysm.

subsequently plateaued (Figure $2 \mathrm{~A}$ ). In contrast, the annualized proportion of patients affected by delayed discharge for emergency surgery continued to rise throughout the study period. There was little seasonal variation in delayed discharge for patients who underwent emergency surgery, but a small reduction was seen over the summer months and in December for patients who underwent elective surgery (Figure 2B). Hospital days attributed to delayed discharge accounted for a median of $21 \%$ to $36 \%$ of total hospital days for the various procedures in the elective surgery group and a median of $16 \%$ to $42 \%$ of total hospital days for the various procedures in the emergency surgery group (Figure 3).

\section{Determinants of delayed discharge}

Differences in patient and hospital characteristics between patients who were and were not affected by delayed discharge are summarized in Table 2 for the elective surgery group and in Table 3 for the emergency surgery group. In both cohorts, delayed discharge more commonly affected older patients (for elective surgery, mean age $75 \mathrm{yr}$ for alternate level of care patients v. $67 \mathrm{yr}$ for non-alternate level of care patients; for emergency surgery, mean age $80 \mathrm{yr}$ v. $71 \mathrm{yr}$ ), women (for elective surgery, $59.1 \%$ v. $51.1 \%$; for emergency surgery, $59.5 \%$ v. $47.0 \%$ ), individuals with greater levels of comorbidity, those residing in urban environments and those from neighbourhoods with lower median household income. Postoperative complications were more common in patients affected by delayed discharge in both the elective surgery group (34.3\% v. $13.8 \%$ ) and the emergency surgery group (29.0\% v. $23.9 \%)$. Most patients with delayed discharge required home care, long-term care or complex continuing care $(89.4 \%$ of those in the elective surgery group and $89.4 \%$ of those in the emergency surgery group).

Patient and hospital factors associated with delayed discharge, adjusted for patient demographic characteristics, comorbidities, and hospital and surgical covariables (model 1), are summarized in Figure 4 and Appendix 1, Table S4. Among patients in the elective surgery group, increased age (OR 1.07 per year, 95\% confidence interval [CI] 1.07-1.07), female sex (OR 1.42, 95\% Cl 1.37-1.47) and comorbidities (e.g., dementia, OR 3.03, 95\% Cl 2.69-3.42; diabetes, OR 1.24, 95\% 1.20-1.29; chronic kidney disease, OR 1.37, 95\% Cl 1.25-1.51; and chronic liver disease, OR $1.58,95 \% \mathrm{Cl} 1.31-1.92)$ were associated with increased adjusted odds of delayed discharge. Conversely, the impact of comorbidities was relatively attenuated in patients who underwent emergency surgery.

Among the surgical procedures, neurosurgery (elective, OR 5.53, 95\% Cl 4.91-6.24; emergency, OR 1.38, 95\% Cl 1.29-1.49) and peripheral arterial disease procedures (elective, OR 4.77, 95\% $\mathrm{Cl}$ 4.35-5.24; emergency, OR 3.96, 95\% Cl 3.72-4.21) were consistently associated with high adjusted odds of delayed discharge. 
Table 2 (part 1 of 2): Patient and hospital characteristics for patients with and without delayed discharge after elective surgery

\begin{tabular}{|c|c|c|c|c|}
\hline \multirow[b]{2}{*}{ Variable } & \multicolumn{3}{|c|}{ Group; no. (\%) of patients* } & \multirow[b]{2}{*}{ Std. diff. $\dagger$} \\
\hline & $\begin{array}{c}\text { Non-ALC } \\
n=577505\end{array}$ & $\begin{array}{c}\text { ALC } \\
n=18277\end{array}$ & $\begin{array}{c}\text { Total } \\
n=595782\end{array}$ & \\
\hline \multicolumn{5}{|l|}{ Patient characteristics } \\
\hline Age, yr, median (IQR) & $67(59-75)$ & $75(67-81)$ & $67(60-75)$ & 0.62 \\
\hline Sex, female & $295358(51.1)$ & $10793(59.1)$ & 306151 (51.4) & 0.16 \\
\hline \multicolumn{5}{|l|}{ Comorbidity } \\
\hline Atrial fibrillation & $22180(3.8)$ & $1663(9.1)$ & $23843(4.0)$ & 0.21 \\
\hline Asthma & $89085(15.4)$ & $3161(17.3)$ & $92246(15.5)$ & 0.05 \\
\hline Coronary artery disease & $47685(8.3)$ & $2514(13.8)$ & $50199(8.4)$ & 0.18 \\
\hline COPD & $124741(21.6)$ & $5230(28.6)$ & $129971(21.8)$ & 0.16 \\
\hline Stroke & $7268(1.3)$ & $613(3.4)$ & $7881(1.3)$ & 0.14 \\
\hline Diabetes mellitus & $156854(27.2)$ & $6774(37.1)$ & $163628(27.5)$ & 0.21 \\
\hline Hypertension & $401546(69.5)$ & $14934(81.7)$ & 416480 (69.9) & 0.29 \\
\hline Chronic liver disease & $2383(0.4)$ & $142(0.8)$ & $2525(0.4)$ & 0.05 \\
\hline Myocardial infarction & $18300(3.2)$ & $1026(5.6)$ & $19326(3.2)$ & 0.12 \\
\hline Cancer & 40034 (6.9) & $1449(7.9)$ & $41483(7.0)$ & 0.04 \\
\hline Renal disease & $7335(1.3)$ & $729(4.0)$ & $8064(1.4)$ & 0.17 \\
\hline Dementia & $2203(0.4)$ & $460(2.5)$ & $2663(0.4)$ & 0.18 \\
\hline Charlson comorbidity index $\geq 2$ & $78893(13.7)$ & $4675(25.6)$ & $83568(14.0)$ & 0.30 \\
\hline Rural residence & $93995(16.3)$ & $1774(9.7)$ & $95769(16.1)$ & 0.20 \\
\hline \multicolumn{5}{|l|}{ Median neighbourhood incomeł } \\
\hline Quintile 1 (lowest) & $97292(16.9)$ & $3938(21.6)$ & $101230(17.1)$ & 0.12 \\
\hline Quintile 2 & $113137(19.7)$ & $3930(21.6)$ & $117067(19.7)$ & 0.05 \\
\hline Quintile 3 & $115044(20.0)$ & $3590(19.7)$ & $118634(20.0)$ & 0.01 \\
\hline Quintile 4 & $122834(21.3)$ & $3400(18.7)$ & $126234(21.3)$ & 0.07 \\
\hline Quintile 5 (highest) & $127049(22.1)$ & $3352(18.4)$ & $130401(22.0)$ & 0.09 \\
\hline \multicolumn{5}{|l|}{ Hospital and surgical characteristics } \\
\hline \multicolumn{5}{|l|}{ Type of surgery } \\
\hline AAA repair & $15704(2.7)$ & $345(1.9)$ & $16049(2.7)$ & 0.06 \\
\hline Joint replacement & 346035 (59.9) & $10546(57.7)$ & 356581 (59.9) & 0.05 \\
\hline Lower gastrointestinal & $69472(12.0)$ & $1487(8.1)$ & 70959 (11.9) & 0.13 \\
\hline Nephrectomy & $16900(2.9)$ & $151(0.8)$ & $17051(2.9)$ & 0.16 \\
\hline Cardiac & $51892(9.0)$ & $1687(9.2)$ & $53579(9.0)$ & 0.01 \\
\hline Lung & $24847(4.3)$ & $218(1.2)$ & $25065(4.2)$ & 0.19 \\
\hline Neurosurgery & $7155(1.2)$ & $488(2.7)$ & $7643(1.3)$ & 0.10 \\
\hline Peripheral arterial disease & $12655(2.2)$ & $1303(7.1)$ & $13958(2.3)$ & 0.24 \\
\hline Spine & $32845(5.7)$ & $2052(11.2)$ & $34897(5.9)$ & 0.20 \\
\hline Duration of surgery, min, median (IQR) & $163(120-215)$ & $168(129-217)$ & $163(120-215)$ & 0.10 \\
\hline No. of hospital beds, median (IQR) & $373(291-513)$ & $423(298-527)$ & $373(291-513)$ & 0.24 \\
\hline Teaching hospital§ & $195473(37.2)$ & $7431(44.8)$ & $202904(37.4)$ & 0.16 \\
\hline Surgical volume, median (IQR)ף & $12663(7519-17719)$ & $13472(7859-20023)$ & $12663(7535-17719)$ & 0.10 \\
\hline \multicolumn{5}{|l|}{ Perioperative care } \\
\hline ICU admission $\leq 24 \mathrm{~h}$ after surgery $\S$ & $54915(10.4)$ & $3032(18.3)$ & $57947(10.7)$ & 0.22 \\
\hline ICU admission $>24 \mathrm{~h}$ after surgery§ & $4775(0.9)$ & $690(4.2)$ & $5465(1.0)$ & 0.21 \\
\hline
\end{tabular}


Table 2 (part 2 of 2): Patient and hospital characteristics for patients with and without delayed discharge

after elective surgery

\begin{tabular}{|c|c|c|c|c|}
\hline \multirow[b]{2}{*}{ Variable } & \multicolumn{3}{|c|}{ Group; no. (\%) of patients* } & \multirow[b]{2}{*}{ Std. diff. $\dagger$} \\
\hline & $\begin{array}{c}\text { Non-ALC } \\
n=577505\end{array}$ & $\begin{array}{c}\text { ALC } \\
n=18277\end{array}$ & $\begin{array}{c}\text { Total } \\
n=595782\end{array}$ & \\
\hline Intra-arterial line & $131222(22.7)$ & $5350(29.3)$ & $136572(22.9)$ & 0.15 \\
\hline Central venous line & $21874(3.8)$ & $1028(5.6)$ & $22902(3.8)$ & 0.09 \\
\hline \multicolumn{5}{|l|}{ Postoperative outcomes } \\
\hline Total hospital stay, d, median (IQR) & $4(3-6)$ & $10(7-17)$ & $4(3-6)$ & 1.57 \\
\hline ALC stay, d, median (IQR) & $0(0-0)$ & $3(2-6)$ & $0(0-0)$ & 80.72 \\
\hline DAH30, d, median (IQR) & $26(24-27)$ & $20(11-23)$ & $26(24-27)$ & 1.46 \\
\hline DAH90, d, median (IQR) & $86(83-87)$ & $79(66-83)$ & $86(83-87)$ & 1.41 \\
\hline DAH180, d, median (IQR) & $175(173-177)$ & $167(151-173)$ & $175(172-177)$ & 1.34 \\
\hline Complication & $79951(13.8)$ & $6274(34.3)$ & $86225(14.5)$ & 0.49 \\
\hline \multicolumn{5}{|l|}{ Discharge disposition } \\
\hline Home with home care & $214490(37.1)$ & $4189(22.9)$ & $218679(36.7)$ & 0.31 \\
\hline Home independently & $293601(50.8)$ & $1433(7.8)$ & 295034 (49.5) & 1.07 \\
\hline Long-term or complex continuing care & $62146(10.8)$ & $12156(66.5)$ & $74302(12.5)$ & $1.4 \underline{U}$ \\
\hline Other ${ }^{\star *}$ & $7268(1.3)$ & $499(2.7)$ & $7767(1.3)$ & 0.11 \\
\hline \multicolumn{5}{|c|}{ 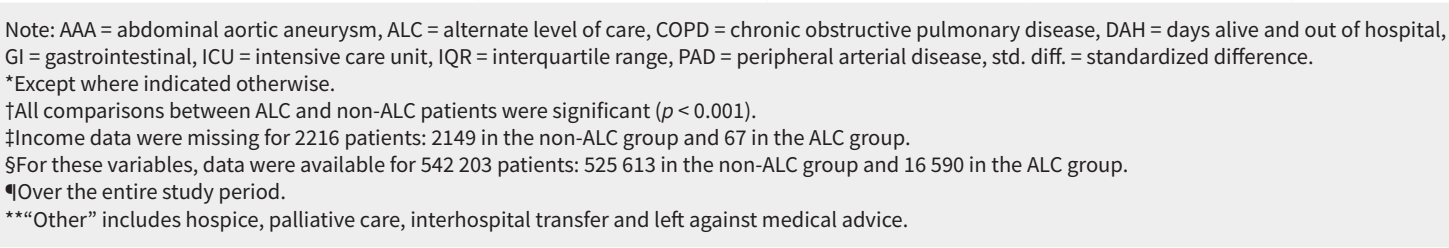 } \\
\hline
\end{tabular}

Increasing hospital size (in terms of number of beds) was associated with higher odds of delayed discharge in both surgical groups (Appendix 1, Figure S1). Models for elective and emergency surgery remained unchanged upon addition of postoperative complications (model 2 ) to the covariables used in model 1 , although complications increased the odds of delayed discharge (elective, OR 2.89, 95\% Cl 2.78-3.00; emergency, OR 1.65, 95\% Cl 1.60-1.70). The individual admitting hospital was a determinant of patients' likelihood of delayed discharge, with intraclass coefficients of $11 \%$ (median OR 1.8) and $7.7 \%$ (median OR 1.6) for the elective and emergency surgery cohorts, respectively.

\section{Interpretation}

Although most of the patients in this study had undergone elective surgery, we found that delayed discharge was a larger problem for patients who underwent emergency surgery than for those who underwent elective surgery. Delayed discharge after emergency surgery is increasing and exceeds the overall national average of $13 \% .{ }^{5}$ We found wide variation in risk of delayed discharge between different surgery types. This may be partially attributable to inherent differences in patient case-mix and postoperative care needs, such as mobility concerns for amputees, functional and cognitive changes in neurosurgical patients and rehabilitation needs after orthopedic procedures. The variation may also be explained by differences in care planning between surgery types. For example, patients who undergo transplant or cardiac surgery receive highly organized multidisciplinary care within structured process pathways before and after surgery. ${ }^{24,25}$ This care model is resource-intensive but facilitates efficient and safe patient discharge.

We found that expected patient factors, such as advanced age and chronic disease, were consistently associated with discharge delay in patients undergoing elective surgery, but this association was diminished among patients needing emergency surgery. Patients undergoing emergency surgery have several unique characteristics that affect discharge planning and postoperative recovery. They often present with acute illnesses and physiologic derangement (e.g., sepsis, dehydration, electrolyte abnormalities, altered vital signs, confusion) that require treatment; they are previously unselected for surgery, with possibly higher baseline risk and poor physical functioning; they may receive surgical care from teams that do not routinely perform certain procedures; and they may be placed on wards where staff are less familiar with the provision of postsurgical care, especially during periods of high hospital bed occupancy. ${ }^{26,27}$ These factors are not captured in administrative data and may lead to a deviation from normal care pathways and discharge planning.

We also found that delayed discharge affected larger hospitals and was a greater problem in urban settings. This may be 
Table 3 (part 1 of 2): Patient and hospital characteristics for patients with and without delayed discharge after emergency surgery

\begin{tabular}{|c|c|c|c|c|}
\hline \multirow[b]{2}{*}{ Variable } & \multicolumn{3}{|c|}{ Group; no. (\%) of patients* } & \multirow[b]{2}{*}{ Std. diff. $\dagger$} \\
\hline & $\begin{array}{c}\text { Non-ALC } \\
n=145033\end{array}$ & $\begin{array}{c}\text { ALC } \\
n=35445\end{array}$ & $\begin{array}{c}\text { Total } \\
n=180478\end{array}$ & \\
\hline \multicolumn{5}{|l|}{ Patient characteristics } \\
\hline Age, yr, median (IQR) & $71(60-81)$ & $80(71-86)$ & $73(62-83)$ & 0.57 \\
\hline Sex, female & $68200(47.0)$ & $21081(59.5)$ & $89281(49.5)$ & 0.25 \\
\hline \multicolumn{5}{|l|}{ Comorbidity } \\
\hline Atrial fibrillation & $14054(9.7)$ & $4921(13.9)$ & $18975(10.5)$ & 0.13 \\
\hline Asthma & $19991(13.8)$ & $5325(15.0)$ & $25316(14.0)$ & 0.04 \\
\hline Coronary artery disease & $35213(24.3)$ & $5461(15.4)$ & $40674(22.5)$ & 0.22 \\
\hline COPD & $39013(26.9)$ & 11309 (31.9) & $50322(27.9)$ & 0.11 \\
\hline Stroke & $5427(3.7)$ & $2136(6.0)$ & $7563(4.2)$ & 0.11 \\
\hline Diabetes mellitus & $49836(34.4)$ & $13311(37.6)$ & $63147(35.0)$ & 0.07 \\
\hline Hypertension & $106934(73.7)$ & $28869(81.4)$ & $135803(75.2)$ & 0.19 \\
\hline Chronic liver disease & $3237(2.2)$ & $779(2.2)$ & $4016(2.2)$ & 0 \\
\hline Myocardial infarction & $20252(14.0)$ & $2881(8.1)$ & $23133(12.8)$ & 0.19 \\
\hline Cancer & $14697(10.1)$ & $3278(9.2)$ & $17975(10.0)$ & 0.03 \\
\hline Renal disease & $9656(6.7)$ & $2702(7.6)$ & $12358(6.8)$ & 0.04 \\
\hline Dementia & $7493(5.2)$ & $3263(9.2)$ & $10756(6.0)$ & 0.16 \\
\hline Charlson comorbidity index $\geq 2$ & $49777(34.3)$ & $13197(37.2)$ & $62974(34.9)$ & 0.06 \\
\hline Rural residence & $18055(12.5)$ & $2210(6.2)$ & $20265(11.2)$ & 0.21 \\
\hline \multicolumn{5}{|l|}{ Median neighbourhood income } \\
\hline Quintile 1 (lowest) & $30140(20.9)$ & $8512(24.1)$ & $38652(21.5)$ & 0.08 \\
\hline Quintile 2 & $29589(20.5)$ & $7364(20.9)$ & $36953(20.6)$ & 0.01 \\
\hline Quintile 3 & $28420(19.7)$ & $6513(18.5)$ & $34933(19.5)$ & 0.03 \\
\hline Quintile 4 & $28947(20.1)$ & $6402(18.2)$ & $35349(19.7)$ & 0.05 \\
\hline Quintile 5 (highest) & $27170(18.8)$ & $6480(18.4)$ & $33650(18.7)$ & 0.01 \\
\hline \multicolumn{5}{|l|}{ Hospital and surgical characteristics } \\
\hline \multicolumn{5}{|l|}{ Type of surgery } \\
\hline AAA repair & $3018(2.1)$ & $255(0.7)$ & $3273(1.8)$ & 0.12 \\
\hline Hip fixation & $16825(11.6)$ & $7331(20.7)$ & $24156(13.4)$ & 0.25 \\
\hline Joint replacement & $31064(21.4)$ & $14156(39.9)$ & $45220(25.1)$ & 0.41 \\
\hline Lower gastrointestinal & $27927(19.3)$ & $3363(9.5)$ & $31290(17.3)$ & 0.28 \\
\hline Transplant & $7590(5.2)$ & $350(1.0)$ & $7940(4.4)$ & 0.25 \\
\hline Cardiac & $32164(22.2)$ & $1269(3.6)$ & $33433(18.5)$ & 0.58 \\
\hline Neurosurgery & $11838(8.2)$ & $1976(5.6)$ & $13814(7.7)$ & 0.10 \\
\hline Peripheral arterial disease & $8085(5.6)$ & $4135(11.7)$ & $12220(6.8)$ & 0.22 \\
\hline Spine & $6522(4.5)$ & $2610(7.4)$ & $9132(5.1)$ & 0.12 \\
\hline Trauma admission & $48603(33.5)$ & $21745(61.3)$ & $70348(39.0)$ & 0.58 \\
\hline Duration of surgery, min, median (IQR) & $165(102-253)$ & $118(86-173)$ & $151(98-241)$ & 0.46 \\
\hline No. of hospital beds, median (IQR) & $317(211-423)$ & $291(209-380)$ & $310(211-419)$ & 0.14 \\
\hline Teaching hospital§ & $49561(43.9)$ & $13529(39.6)$ & $63090(42.9)$ & 0.09 \\
\hline Surgical volume, median (IQR)ฯ & $4842(2750-9138)$ & $3904(2481-7708)$ & $4242(2605-9138)$ & 0.23 \\
\hline \multicolumn{5}{|l|}{ Perioperative care } \\
\hline ICU admission $\leq 24 \mathrm{~h}$ after surgery§ & 20401 (18.1) & 4998 (14.6) & 25399 (17.3) & 0.09 \\
\hline
\end{tabular}


Table 3 (part 2 of 2): Patient and hospital characteristics for patients with and without delayed discharge

after emergency surgery

ICU admission $>24 \mathrm{~h}$ after surgery§

Intra-arterial line

Central venous line

\section{Postoperative outcomes}

Total hospital stay, d, median (IQR)

ALC stay, d, median (IQR)

DAH30, d, median (IQR)

DAH90, d, median (IQR)

DAH180, d, median (IQR)

Complication

\section{Discharge disposition}

Home with home care

Home independently

Long-term or complex continuing care

Other $^{\star *}$

\section{Group; no. (\%) of patients}

\begin{tabular}{cccc}
$\begin{array}{c}\text { Non-ALC } \\
\boldsymbol{n}=\mathbf{1 4 5} \text { 033 }\end{array}$ & $\begin{array}{c}\text { ALC } \\
\boldsymbol{n}=\mathbf{3 5 4 4 5}\end{array}$ & $\begin{array}{c}\text { Total } \\
\boldsymbol{n}=\mathbf{1 8 0 4 7 8}\end{array}$ & Std. diff. $\dagger$ \\
\hline $2456(2.2)$ & $978(2.9)$ & $3434(2.3)$ & 0.21 \\
\hline $44407(30.6)$ & $8998(25.4)$ & $53405(29.6)$ & 0.12 \\
$15516(10.7)$ & $2126(6.0)$ & $17642(9.8)$ & 0.17 \\
\hline $9(6-15)$ & $20(12-38)$ & & \\
\hline $0(0-0)$ & $6(3-14)$ & $0(7-18)$ & 1.06 \\
\hline $21(11-25)$ & $11(0-20)$ & $20(7-24)$ & 12.5 \\
\hline $80(62-84)$ & $66(27-78)$ & $78(54-84)$ & 0.77 \\
$169(139-174)$ & $148(70-167)$ & $166(120-173)$ & 0.68 \\
\hline $34618(23.9)$ & $10272(29.0)$ & $44890(24.9)$ & 0.64 \\
\hline $37537(25.9)$ & & & 0.22 \\
\hline $55435(38.2)$ & $1438(4.1)$ & $42626(23.6)$ & 0.29 \\
\hline $37145(25.6)$ & $26661(75.2)$ & $56873(31.5)$ & 0.92 \\
\hline $14916(10.3)$ & $2257(6.4)$ & $17173(9.5)$ & 0.14 \\
\hline
\end{tabular}

Note: $\mathrm{AAA}=$ abdominal aortic aneurysm, ALC = alternate level of care, $\mathrm{COPD}=$ chronic obstructive pulmonary disease, $\mathrm{DAH}=$ days alive and out of hospital, $\mathrm{GI}=$ gastrointestinal, $\mathrm{ICU}=$ intensive care unit, $\mathrm{IQR}=$ interquartile range, $\mathrm{PAD}=$ peripheral arterial disease, std. diff. = standardized difference.

${ }^{\star}$ Except where indicated otherwise.

†All comparisons between ALC and non-ALC patients were significant $(p<0.001)$, except for chronic liver disease $(p=0.7)$.

fIncome data were missing for 941 patients: 767 in the non-ALC group and 174 in the ALC group.

$\S$ For these variables, data were available for 147045 patients: 112869 in the non-ALC group and 34176 in the ALC group.

IOver the entire study period.

**"Other" includes hospice, palliative care, interhospital transfer and left against medical advice.

due to more patients living in urban environments, the location of specialist surgical services and a possible mismatch between the surgical population and availability of chronic care beds in different health care regions..$^{20,28}$ The higher intraclass coefficient and median OR values indicate that the probability of the alternate level of care designation was partially driven by the particular hospitals to which patients were admitted. This effect is likely attributable to variation in postoperative care practices and efficiency regarding discharge of patients.

Delayed discharge has wide health system implications for timely access to acute care beds, including increases in recommended wait times for elective surgery, cancellation of planned surgical procedures and longer wait times for acutely ill patients in emergency departments who need a hospital bed. ${ }^{20,29}$ Many hospitals running at high occupancy rates experience "gridlock" in patient flow, leading to delivery of care in unsafe environments (i.e., "hallway medicine"). ${ }^{30}$ For patients, delayed discharge increases the risk of nosocomial infections and pressure sores and slows mobilization, all of which have downstream consequences for inpatient and outpatient services. ${ }^{3}$ These concerns are seen in many publicly funded health care systems, but are also important for self-paying or Medicare/Medicaid patients in the United States. ${ }^{3,6}$
In our study, most patients affected by delayed discharge required continuing care services in the community from home care or in facilities that offer skilled nursing care. Timely access to continuing care facilities is essential to reduce delayed discharge but is challenged by rising demand and longer wait lists for longterm care homes, as well as by the limited availability of home care. ${ }^{31}$ Health policy leaders can promote safer and faster hospital discharge by increasing the availability of community care services. Early discharge planning to assess and implement surgeryand patient-specific care requirements to aid recovery could also prevent delayed discharge. Evidence indicates that discharge planning should commence early, possibly even before hospitalization for acute care, with the benefits of shortening hospital stays, preventing hospital readmission and improving patient satisfaction. ${ }^{32}$ The introduction of integrated care pathways that incorporate access to rehabilitation facilities after elective hip and knee surgery has led to progress in this area. ${ }^{33,34}$

Important strengths of our study were the use of populationlevel databases that have tracked delayed discharge information within Canadian hospitals for many years and use of a homogeneous patient cohort. ${ }^{1}$ By comparison, prior research has involved single-centre studies that used nonstandardized local or insurer-based definitions of prolonged hospitalization for 

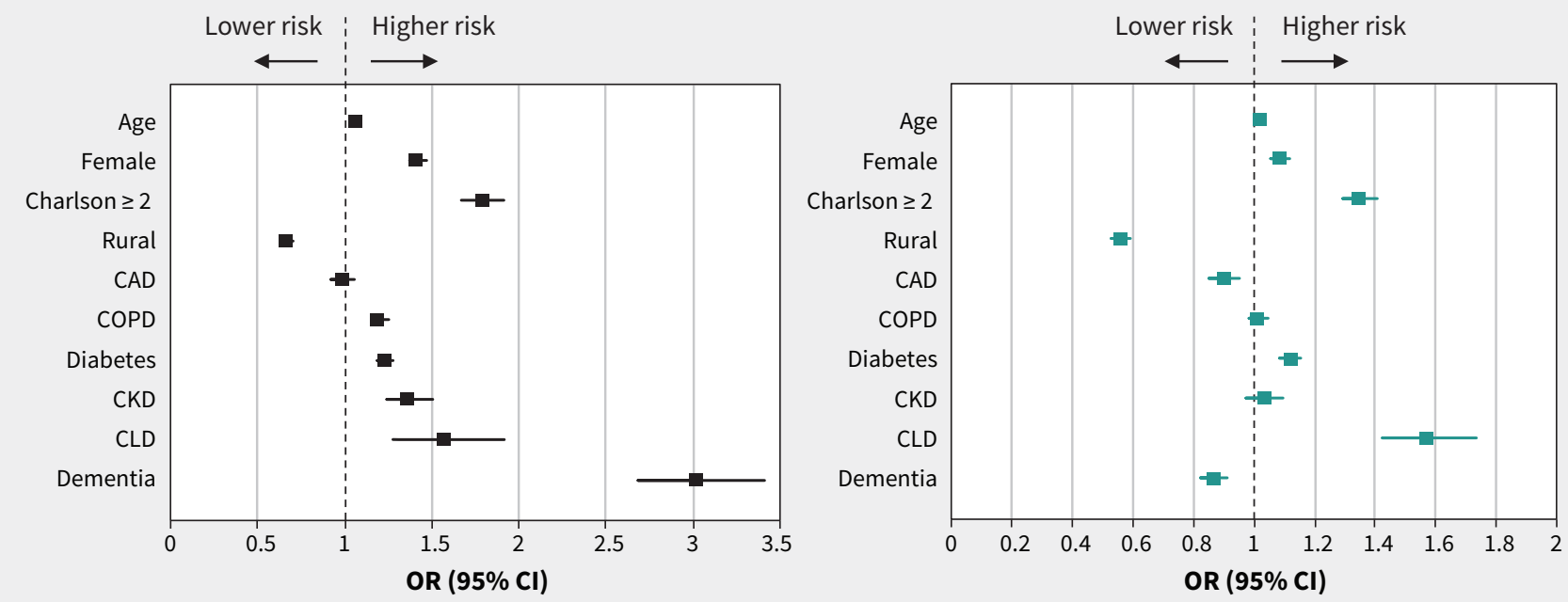

B

Elective surgery

Emergency surgery
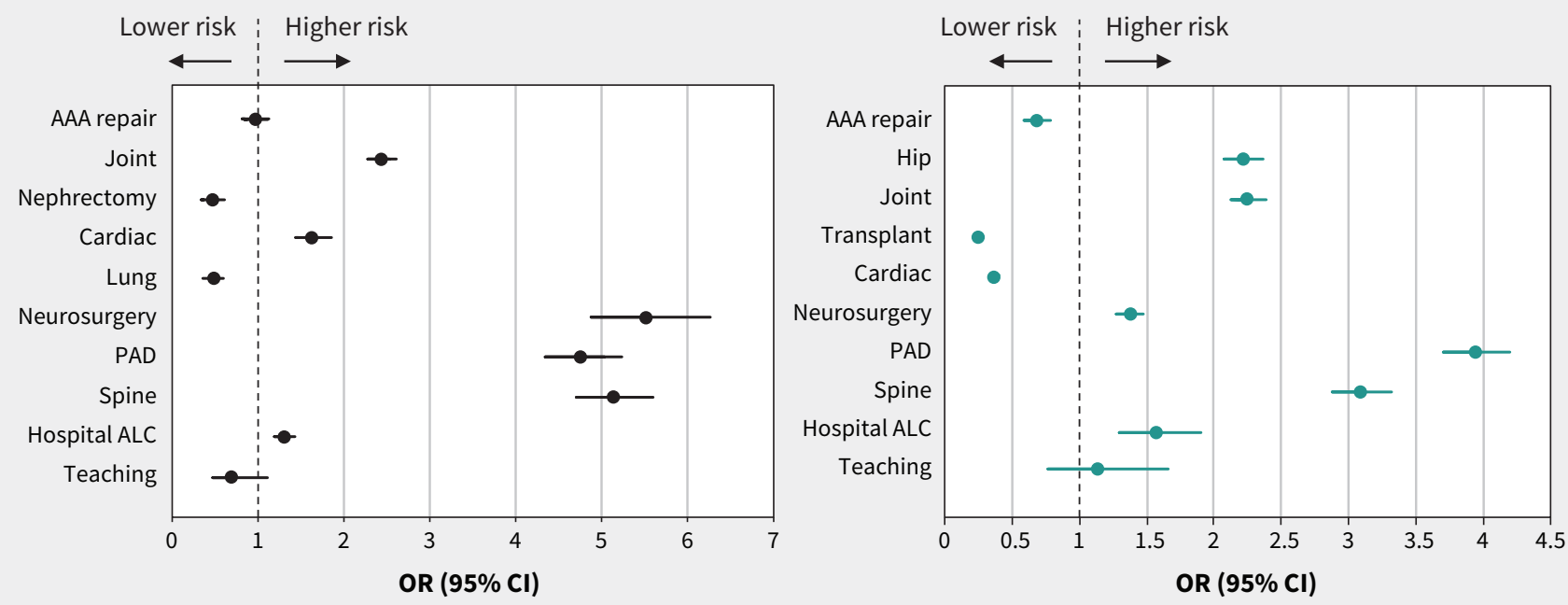

Figure 4: Forest plots of selected covariables associated with the outcome of delayed discharge (binary outcome) for elective and emergency surgery. (A) The upper figures show patient characteristics, including comorbidities. For age, the OR is per year. (B) The lower figures show types of surgery and hospital characteristics. The range of the $x$ axis is different for each figure. Note: $A A A=$ abdominal aortic aneurysm, $A L C=$ alternate level of care, $C A D=$ coronary artery disease, $\mathrm{Cl}=$ confidence interval, $\mathrm{COPD}=$ chronic obstructive pulmonary disease, $\mathrm{CKD}=$ chronic kidney disease, $\mathrm{CLD}=$ chronic liver disease, $\mathrm{OR}=$ odds ratio, $\mathrm{PAD}=$ peripheral arterial disease.

nonmedical reasons. Prior studies showed differing rates of delayed discharge: $7 \%$ in a mixed medical-surgical cohort in France, ${ }^{35} 21 \%$ in a British vascular surgery study ${ }^{36}$ and $5 \%$ among trauma patients in a US hospital. ${ }^{6}$

\section{Limitations}

We note the following limitations for this study. Patient misclassification was possible because the code for alternate level of care may be applied to patients who cannot be moved between hospital departments. However, validation studies have shown that the alternate level of care code largely captures patients waiting for transfer to community care settings. ${ }^{1,37}$
The designation of alternate level of care is a clinical responsibility. Although there is good agreement between charts and databases in terms of recording alternate level of care, the initial recording of this status must take place, which raises the possibility of underreporting; if so, the true effects are likely to have been greater than what is reported here. $\mathrm{CIHI}$ data have shown that about $8 \%$ of patients with prolonged stays who were discharged to a continuing care facility were not designated as alternate level of care. ${ }^{1}$

Our retrospective study was open to residual confounding because the data sources lacked physiologic variables (e.g., heart rate, blood pressure) that could have provided more information about severity of illness. 
We examined delayed discharge at a population level rather than looking at differences among hospitals, and rates of delayed discharge may vary among health regions, given the associated differences in availability of post-acute care community resources. Further examination of this possible interhospital variation will require geospatial studies and detailed data on the supply of local community services.

Given that we studied patients who required a minimum hospital admission of 2 days, our observations may have been affected by survivorship bias. Our aim, however, was to create a clinically representative patient cohort that would likely be most affected by delayed nonmedical discharge. We did not aim to examine differences in discharge planning between surgical specialties, which may explain, in part, the observed differences in rates of delayed discharge. While important, such information is not captured by available databases and would require evaluation using a qualitative study.

\section{Conclusion}

Delay in discharge from hospital for nonmedical reasons was higher after emergency surgery than after elective surgery, and rates of delayed discharge varied across surgery type. Both patient- and hospital-level factors were associated with delayed discharge, including older age, female sex, chronic disease burden and larger hospital size. Optimizing discharge planning before or at the time of admission, evaluating the variation in delayed discharge at the hospital level and improving local access to community care services could be next steps in addressing this problem.

\section{References}

1. Analysis in brief: taking health information further - alternate level of care in Canada. Ottawa: Canadian Institute for Health Information; 2009.

2. Green MA, Dorling D, Minton J, et al. Could the rise in mortality rates since 2015 be explained by changes in the number of delayed discharges of NHS patients? J Epidemiol Community Health 2017;71:1068-71.

3. Rojas-García A, Turner S, Pizzo E, et al. Impact and experiences of delayed discharge: a mixed-studies systematic review. Health Expect 2018;21:41-56.

4. Lavergne MR. Regional variation in alternate level of care (ALC) service use in British Columbia hospitals: an opportunity for intervention? Vancouver: Institute for Health System Transformation \& Sustainability; 2015.

5. Sutherland JM, Crump TR. Alternative level of care: Canada's hospital beds, the evidence and options. Healthc Policy 2013;9:26-34.

6. Hwabejire JO, Kaafarani HMA, Imam AM, et al. Excessively long hospital stays after trauma are not related to the severity of illness: Let's aim to the right target! JAMA Surg 2013;148:956-61.

7. Stock D, Cowie C, Chan V, et al. Determinants of alternate-level-of-care delayed discharge among acute care survivors of hypoxic-ischemic brain injury: a population-based cohort study. CMAJ Open 2016;4:E689-97.

8. McCloskey R, Jarrett P, Stewart C, et al. Alternate level of care patients in hospitals: What does dementia have to do with this? Can Geriatr J 2014;17: 88-94.

9. Fowler AJ, Abbott TEF, Prowle J, et al. Age of patients undergoing surgery. Br J Surg 2019;106:1012-8.

10. Southern DA, Burnand B, Droesler SE, et al. Deriving ICD-10 codes for patient safety indicators for large-scale surveillance using administrative hospital data. Med Care 2017;55:252-60.

11. Jerath A, Austin PC, Wijeysundera DN. Days alive and out of hospital: validation of a patient-centered outcome for perioperative medicine. Anesthesiology 2019;131:84-93.

12. Jerath A, Laupacis A, Austin PC, et al. Intensive care utilization following major noncardiac surgical procedures in Ontario, Canada: a population based study. Intensive Care Med 2018;44:1427-35.
13. von Elm E, Altman DG, Egger M, et al.; STROBE Initiative. The Strengthening the Reporting of Observational Studies in Epidemiology (STROBE) statement: guidelines for reporting observational studies. Ann Intern Med 2007;147:573-7.

14. Fleisher LA, Fleischmann KE, Auerbach AD, et al.; American College of Cardiology; American Heart Association. 2014 ACC/AHA guideline on perioperative cardiovascular evaluation and management of patients undergoing noncardiac surgery: a report of the American College of Cardiology/American Heart Association Task Force on Practice Guidelines. J Am Coll Cardiol 2014;64:e77-137.

15. Jerath A, Austin PC, Ko DT, et al. Socioeconomic status and days alive and out of hospital after major elective noncardiac surgery: a population-based cohort study. Anesthesiology 2020;132:713-22.

16. Khuri SF, Henderson WG, DePalma RG, et al.; Participants in the VA National Surgical Quality Improvement Program. Determinants of long-term survival after major surgery and the adverse effect of postoperative complications. Ann Surg 2005;242:326-41, discussion 341-3.

17. Guidelines to support ALC designation. Ottawa: Canadian Institute for Health Information. Available: www.cihi.ca/en/alc (accessed 2019 Dec. 1).

18. Juurlink D, Preyra C, Croxford R, et al. Canadian Institute for Health Information Discharge Abstract Database: a validation study - ICES Investigative Report. Toronto: ICES; 2006:1-77.

19. Data quality study of the 2015-2016 Discharge Abstract Database: a focus on hospital harm. Ottawa: Canadian Institute for Health Information; 2016. Available: https://secure.cihi.ca/free_products/DAD_15_16_Reab_Report_EN.pdf (accessed 2020 Mar. 17).

20. Measuring up 2018: a yearly report on how Ontario's health system is performing. Toronto: Health Quality Ontario; 2018. Available: www.hqontario.ca/Portals/0/ Documents/pr/measuring-up-2018-en.pdf (accessed 2020 Jan. 1).

21. Alternate level of care and emergency room. Toronto: Ontario Hospital Association. Available: https://www.oha.com/health-system-transformation/alternate -level-of-care-and-emergency-room (accessed 2020 Mar. 16).

22. Harrell FE Jr. Regression modeling strategies. 2nd ed. Cham (Switzerland): Springer International Publishing; 2015.

23. Austin PC, Merlo J. Intermediate and advanced topics in multilevel logistic regression analysis. Stat Med 2017;36:3257-77.

24. Brady S, Purdham D, Oh P, et al. Clinical and sociodemographic correlates of referral for cardiac rehabilitation following cardiac revascularization in Ontario. Heart Lung 2013;42:320-5.

25. Stoicea N, You T, Eiterman A, et al. Perspectives of post-acute transition of care for cardiac surgery patients. Front Cardiovasc Med 2017;4:70.

26. Columbus AB, Morris MA, Lilley EJ, et al. Critical differences between elective and emergency surgery: identifying domains for quality improvement in emergency general surgery. Surgery 2018;163:832-8.

27. Ingraham AM, Cohen ME, Raval MV, et al. Comparison of hospital performance in emergency versus elective general surgery operations at 198 hospitals. J Am Coll Surg 2011;212:20-8.e1.

28. Andrulis DP, Duchon LM. The changing landscape of hospital capacity in large cities and suburbs: implications for the safety net in metropolitan America. J Urban Health 2007;84:400-14.

29. Wong DJN, Harris SK, Moonesinghe SR, et al. Cancelled operations: a 7-day cohort study of planned adult inpatient surgery in 245 UK National Health Service hospitals. Br J Anaesth 2018;121:730-8.

30. Hallway health care: a system under strain - 1st interim report from the Premier's Council on Improving Healthcare and Ending Hallway Medicine. Toronto: Ministry of Health and Long-Term Care; 2019. Available: www.health.gov.on.ca/en/public/ publications/premiers_council/docs/premiers_council_report.pdf (accessed 2019 Sept. 3).

31. This is long-term care 2018. Toronto: Ontario Long Term Care Association; 2018. Available: www.oltca.com/OLTCA/Documents/Reports/Thisislongtermcare2018. pdf (accessed 2018 Aug. 10).

32. Gonçalves-Bradley DC, Lannin NA, Clemson LM, et al. Discharge planning from hospital. Cochrane Database Syst Rev 2016;2016:CD000313.

33. Sutherland J, Hellsten E. Integrated funding: connecting the silos for the healthcare we need. Commentary No 463. Toronto: C.D. Howe Institute; 2017.

34. Bundled care (integrated funding models). Toronto: Ministry of Health and Long-Term Care; 2018.

35. d'Alché-Gautier MJ, Maïza D, Chastang F. Assessing the appropriateness of hospitalisation days in a French university hospital. Int J Health Care Qual Assur Inc Leadersh Health Serv 2004;17:87-91.

36. Houghton JSM, Urriza Rodriguez D, Weale AR, et al. Delayed discharges at a major arterial centre: a 4-month cross-sectional study at a single specialist vascular surgery ward. BMJ Open 2016;6:e011193.

37. Seniors and alternate level of care: building on our knowledge. Ottawa: Canadian Institute for Health Information; 2012. 
Competing interests: None declared.

This article has been peer reviewed.

Affiliations: Sunnybrook Research Institute (Jerath, Austin, Ko, H. Wijeysundera, Fremes, Karanicolas), Division of Cardiology (Ko, $\mathrm{H}$. Wijeysundera), Division of Cardiac Surgery (Fremes) and Department of General Surgery (Karanicolas), Sunnybrook Health Sciences Centre; Department of Anesthesia and Pain Medicine (Jerath, D. Wijeysundera), University of Toronto; ICES Central (Jerath, Austin, Ko, $\mathrm{H}$. Wijeysundera, Fremes, Karanicolas, McCormack, D. Wijeysundera), Toronto, Ont.; School of Population and Public Health (Sutherland), University of British Columbia, Vancouver, BC; Li Ka Shing Knowledge Institute (D. Wijeysundera), St. Michael's Hospital, Toronto, Ont.

Contributors: Angela Jerath conceived the study, performed the analysis and drafted the manuscript. Jason Sutherland contributed to the analytical design, interpretation of the data and drafting of the manuscript. Peter Austin contributed to the study design (including analytical design) and interpretation of the data. Dennis Ko, Harindra Wijeysundera, Stephen Fremes and Paul Karanicolas supported the analytical design and interpretation of the data. Daniel McCormack created the study cohort and linked the databases. Duminda Wijeysundera contributed to the study design, data interpretation and drafting of manuscript. All of the authors revised the manuscript for important intellectual content, approved the version to be published and agreed to be accountable for the work.

Funding: This study was supported by a grant from the Academic Health Science Centre Alternative Funding Plan Innovation Fund, the Canadian Anesthesiologists' Society Research Award and the Improving the Heart and Brain Health for Women in Canada award (sponsored by the Heart and Stroke Foundation of Canada and Health Canada). Angela Jerath is supported in part by a Merit Award from the Department of Anesthesia and Pain Medicine at the University of Toronto. Peter Austin and Dennis Ko are supported in part by Mid-Career Investigator Awards from the Heart and Stroke Foundation of Canada. Harindra Wijeysundera is supported by a Phase 2 Clinician Scientist Award from the Heart and Stroke Foundation of Canada. Duminda Wijeysundera is supported in part by a New Investigator Award from the Canadian Institutes of Health
Research, an Excellence in Research Award from the Department of Anesthesia and Pain Medicine at the University of Toronto and the Endowed Chair in Translational Anesthesiology Research at St. Michael's Hospital and University of Toronto.

Data sharing: The original data and code for this study are held at ICES. Requests for data sharing can be made to the corresponding author, Angela Jerath, and will be subject to the terms of ICES data-sharing agreements. Further information can be found at https:// www.ices.on.ca/Data-and-Privacy/ICES-data/ Working-with-ICES-Data

Disclaimer: This study was supported by ICES, which is funded by an annual grant from the Ontario Ministry of Health and LongTerm Care (MOHLTC). The opinions, results and conclusions reported in this paper are those of the authors and are independent from the funding sources. No endorsement by ICES or the Ontario MOHLTC is intended or should be inferred.

Accepted: June 29, 2020

Correspondence to: Angela Jerath, Angela. Jerath@mail.utoronto.ca 